\title{
Non-pharmacological and non-surgical strategies to promote sexual recovery for men with erectile dysfunction
}

\author{
Richard Wassersug ${ }^{1,2}$, Erik Wibowo ${ }^{3}$ \\ ${ }^{1}$ Australian Research Centre in Sex, Health and Society, La Trobe University, Melbourne, Australia; ${ }^{2}$ Department of Urologic Sciences, University of \\ British Columbia, Vancouver, Canada; ${ }^{3}$ British Columbia Cancer Agency, Vancouver, Canada \\ Contributions: (I) Conception and design: All authors; (II) Administrative support: E Wibowo; (III) Provision of study materials or patients: None; \\ (IV) Collection and assembly of data: All authors; (V) Data analysis and interpretation: All authors; (VI) Manuscript writing: All authors; (VII) Final \\ approval of manuscript: All authors. \\ Correspondence to: Richard Wassersug. Australian Research Centre in Sex, Health, and Society, La Trobe University, 215 Franklin Street, Melbourne, \\ Victoria 3000, Australia. Email: richard.wassersug@ubc.ca.
}

\begin{abstract}
Erectile dysfunction (ED), the most commonly reported sexual problem for men, reduces the quality of life for both patients and their partners. Even when physiologically effective, long-term adherence to ED treatments is poor. We review here the implication of having patients' partners involved in ED treatment, starting with treatment selection. We suggest that having partners engaged from the outset may promote an erotic association of the treatment with the partner, i.e., conceptually linking the aid to the sexual pleasure that the partner provides. We hypothesize that this erotic association should enhance the sexual aid's effectiveness and might potentially help improve long-term adherence. The primary focus of this review, though, is non-pharmacological and non-surgical options for maintaining sexual activity for men with ED. Though not ED treatments per se, anecdotal data suggest that these options may be effective for some patients and their partners in regaining a satisfying sex life. The aids discussed include external penile prostheses, penile sleeves, and penile support devices. These devices can allow men to participate in penetrative sexual intercourse despite moderate to severe ED. External penile prostheses can be personalized so they match in size and shape a man's normal full erection. Penile sleeves can similarly be customized with a lumen that fits best a patient's penis for optimal tactile stimulation. We review how multi-sensory integration can enhance sexual arousal for men who use such devices, allowing them to achieve orgasm despite intractable ED. Patients are not always advised within ED clinics about these options nor why and how they can facilitate nonerection dependent sexual recovery. Clinicians need to be aware of these devices and their positive attributes, so they can objectively counsel and encourage couples to explore their use as an alternative to more invasive treatments. The most commonly promoted non-medical ED aid offered to patients is the vacuum erection device. We discuss how erections achieved with the vacuum erection device have a "hinge effect", that is an underappreciated barrier to the effectiveness of the erection. With a hinged erection, the penis points downward rather than upward. We show how the normal kinematics of the penis during coitus is not strictly linear (i.e., not uniaxial; not just in-and-out), and is impeded by hinging. Positional adjustment, such as the receptive partner being on top, may help overcome this problem for some couples. Lastly, we suggest that, in the case where ED can be anticipated from a pending medical treatment, such as a prostatectomy, prehabilitative approaches may potentially improve adherence to sexual aid use in the long-term. In conclusion, non-pharmacological and non-surgical options for sexual recovery are available. Scientific studies on the effectiveness of these interventions in restoring satisfying sex are warranted.
\end{abstract}

Keywords: External penile prostheses; penile sleeves; penile support devices; vacuum erection devices; erectile dysfunction (ED)

Submitted Jan 24, 2017. Accepted for publication Mar 30, 2017.

doi: $10.21037 /$ tau.2017.04.09

View this article at: http://dx.doi.org/10.21037/tau.2017.04.09 


\section{Introduction}

Sexual dysfunction can happen in men of any age, although it becomes increasingly common as men get older. Erectile dysfunction (ED), defined as "the consistent or recurrent inability of a man to attain and/or maintain a penile erection sufficient for sexual activity" (1), is the most commonly reported sexual problem for men $(2,3)$. ED can affect men's confidence and self-esteem leading to depression which, in turn, can negatively impact men's intimate relationships and quality of life overall (4-8). As a component to sexual recovery, men need to be educated about strategies for managing ED (9), ideally before the onset of ED.

Currently, many treatments are available for ED, with an oral phosphodiesterase type-5 inhibitors (PDE5i) as the first intervention commonly offered to patients (10-13). This is partly because patients typically prefer the least invasive treatment as an initial intervention (14). However, many PDE5i are not fully effective and in such cases patients may then advance to other treatments, such as intracavernous injections (ICI), the vacuum erection device (VED), or penile implants.

A major concern with all ED treatments is that longterm adherence is poor (15-18). While some men may stop using an ED treatment because of natural recovery of erections, many men with persistent ED nevertheless withdraw from treatment. Failure to acquire erections firm enough for penetrative sex or partner's disinterest are a few reasons for a patient to abandon ED treatment. Other reasons for withdrawing from ED treatments are: concerns about side effects from pharmacological agents (19-21), mechanical failure of penile implants $(22,23)$, and inconvenience or discomfort associated with using ICI and the VED $(24,25)$. Some men who have had penile implants need additional surgeries (23) because of dissatisfactions with surgical outcomes, infection, or mechanical problems with the prosthesis.

There may as well be psychosocial factors accounting for ED treatment abandonment. Some men, for example, adapt to ED during prolonged periods of sexual inactivity before receiving treatment. Partner's disinterest can potentially exacerbate or attenuate patients' acceptance and sustained use of physiologically effective ED treatments $(26,27)$. Often when men are burdened with ED, such as secondary to prostate cancer treatments, their female partners are facing their own changes in sexual function, such as the vaginal drying associated with menopause. This can make sexual recovery for the couple more challenging.
In this article, we focus on the use of non-invasive overthe-counter sexual aids (Figure 1, Table 1) outside of standard ED treatments. These include devices such as external penile prostheses, penile support devices, and penile sleeves. For some men, these aids may be more effective than established ED treatments, particularly when the standard ED treatments are not $100 \%$ effective. Studies on these aids are admittedly sparse and mostly anecdotal, but that should not preclude considering them as therapeutic options. We hope that this article will encourage rigorous and objective research on the efficacy and acceptability of such sexual aids.

There is a growing awareness of the importance of partners in sexual rehabilitation, and how partners' engagement may be key to the long-term adherence to physiologically effective ED treatments. It has long been recognized that restoring full erections does not necessarily translate into a satisfactory sexual life $(26,30)$; rather, a fulfilling sex life typically requires one's partner's engagement. However, how, when, and where to involve partners to maximize that benefit has not been wellinvestigated. Intuitively, for ED treatments to be successful, partners should be included in all aspects of ED care; from the time of assessment and diagnosis, through counseling, to treatment selection, and follow-up $(15,31,32)$.

\section{Perspective on partner engagement}

Involving partners in the management of ED recognizes that ED hinders the sexual life of both patients and their partners $(18,33)$. The perception of how bothersome ED is may differ, though, between patients and partners (15). The sexual desire and functional status of the partner can influence the patient's bother from ED, as well as his interest and adherence to ED treatment. How sexually intimate a couple is may contribute to ED bother for both; for example, an elderly couple that is close and cosupportive, yet have been sexually inactive for a long period of time may be little bothered by ED (34). Furthermore, there are patients who have partners with sexual problems such as vaginal dryness in female partners or ED in male partners; therefore, screening partners' sexual health is also crucial in sexual rehabilitation. Sexual dysfunction is often a complex issue and the dynamic of a couple's sexual relationship before ED diagnosis may contribute to how successful sexual recovery is with treatment $(15,31)$.

The importance of partners in ED management particularly stands out when ED occurs abruptly, for example as an iatrogenic outcome from a prostatectomy. 
A

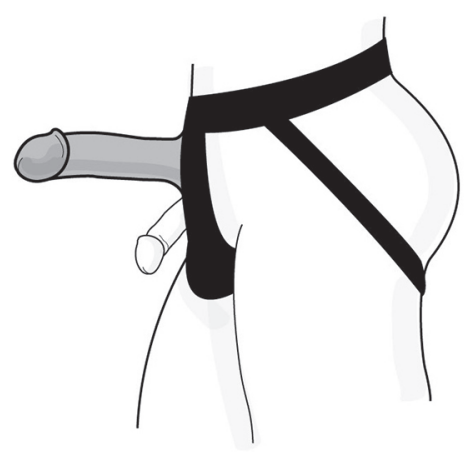

C

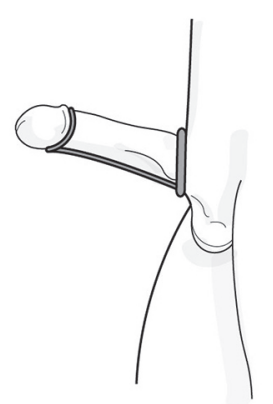

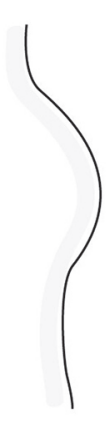

B

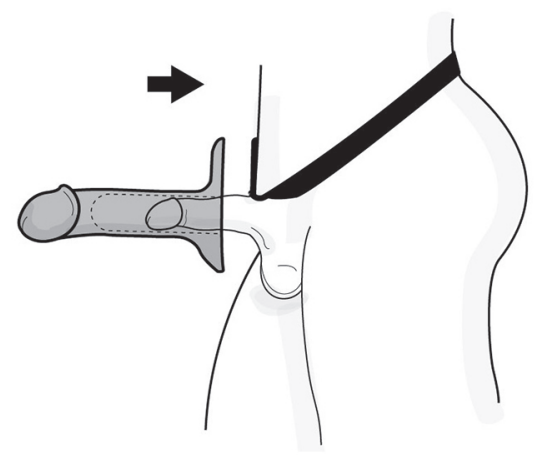

D

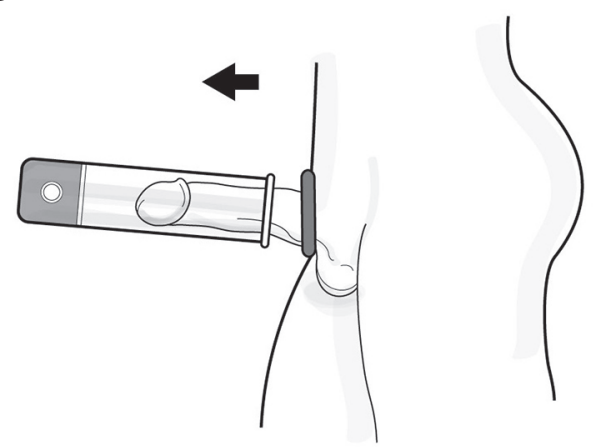

Figure 1 Various external aids for sexual recovery in the face of ED. (A) An external penile prosthesis; also called a belted prosthetic phallus in medicalized language (28) and a strap-on dildo in vernacular English (29). Some men recover orgasmic capability despite severe ED when they use this device for coitus. (B) A penile sleeve. Depending on the size, shape, thickness of sleeves, such aids can be used for sexual intercourse by men with ED. Some versions, like the RxSleeve, are designed to be used with a harness, others not. (C) The Elator, a penile support device. This device can be used for coitus. It works by extending the penile glans away from the base of the penis and bracing the penile shaft. (D) A VED. A commonly recommended device used to induce tumescence in the penile shaft, but erections acquired with a VED suffer from the hinge effect, which interferes with normal penile kinematics during an intercourse (see text and Figure 2). ED, erectile dysfunction; VED, vacuum erection device.

This has led many authors to refer to prostate cancer as a "couple's disease" (35-40). Indeed, all major treatments for localized prostate cancer increase the risk of ED (41-43). In addition, many prostate cancer patients receive androgen deprivation therapy, which reduces libido substantially $(35,44,45)$. Indirectly, but inevitably, the diminished sexual function and desire of patients affect their partners. This has led to clinical psychologists and sex therapists to consistently encourage men with sexual issues to engage their partners in the therapeutic interventions.

When presented with ED treatment options, patients and partners may hold divergent views as to what the best course of action is $(15,31)$. Discord at the outset is a bad sign, given that there is less treatment regret and distress for both prostate cancer patients and partners when they are in accord about his medical treatments [e.g., $(46,47)$ ]. It is reasonable then to presume that this would apply to selecting ED treatments. However, the benefits of engaging partner in patient's ED treatment may extend beyond selecting ED treatments. Partner's engagement can influence the effectiveness of the treatment itself, and possibly even the overall survival in the case of prostate cancer patients. Sexual intimacy, which is rewarding for patients and partners, strengthens spousal bonds and psychosocial support (48). In turn, for prostate cancer patients (whether sexually active or not), the mere fact that they have spousal support confers a benefit in quality of life (49-51) and survival over patients without partners (52).

Kukula et al. (16) proposed a pathway by which partner's involvement in ED treatments might improve treatment effectiveness and patient compliance. They specifically promoted eroticization of ED treatments. When the erectile aid is directly incorporated into the couple's sexual practice, the aid becomes eroticized because it is associated 
Table 1 Comparison of the age of buyers, reason for buying and cost of some selected examples of non-pharmacological and non-surgical sexual aids

\begin{tabular}{|c|c|c|c|}
\hline Sexual aid & $\begin{array}{l}\text { Age range of buyers and } \\
\text { percentage in that range }\end{array}$ & Reasons for buying & Cost per aid (\$US) \\
\hline RxSleeve & $\begin{array}{l}21-40(18 \%) \\
41-50(22 \%) \\
51-60(32 \%) \\
61-70(24 \%) \\
>71(4 \%) \\
\text { Average }=59\end{array}$ & $\begin{array}{l}60 \% \text { ED from } \\
\text { unspecified causes } \\
26 \% \text { ED from prostate } \\
\text { cancer treatments } \\
9 \% \text { recreational use } \\
5 \% \text { others }\end{array}$ & $\begin{array}{l}\text { From } \$ 275 \text { to } \$ 425 \\
\text { Full personalization kit }=\$ 650\end{array}$ \\
\hline Elator & $\begin{array}{l}21-40(7.7 \%) \\
41-50(9.1 \%) \\
51-60(18.7 \%) \\
61-70(37.6 \%) \\
>71(24.4 \%) \\
\text { Average }=62\end{array}$ & $\begin{array}{l}65 \% \text { ED from prostate } \\
\text { cancer treatments } \\
15 \% \text { Venous leakage } \\
\text { from unspecified } \\
\text { causes } \\
15 \% \text { Diabetes } \\
5 \% \text { Other }\end{array}$ & From $\$ 298$ to $\$ 348$ \\
\hline VED & $\begin{array}{l}\text { Data } \\
\text { unavailable }\end{array}$ & $\begin{array}{l}\text { Data } \\
\text { unavailable }\end{array}$ & $\begin{array}{l}\text { From } \$ 160 \text { to } \$ 629 \text { (Erecaid or Esteem systems from Timm } \\
\text { Medical) } \\
\text { From } \$ 95 \text { to } \$ 125 \text { (OwenMumford's Rapport system, Encore or } \\
\text { ImpoAid systems from VitalityMedical.com) } \\
\text { From } \$ 199 \text { to } \$ 648 \text { (Soma Therapy systems from Augusta Medical } \\
\text { Systems) } \\
\text { From } \$ 160 \text { to } \$ 375 \text { (Post-T-Vac systems from PostVac.com) } \\
\text { From } 169 € \text { to } 349 € \approx \$ 178-\$ 363 \text { (ACTIVE, MANUAL or REHABI } \\
\text { systems from MEDintim) } \\
\text { From } \$ 149 \text { to } \$ 199 \text { (AndroVacuum) }\end{array}$ \\
\hline
\end{tabular}

Many VEDs are on the market, priced from $\$ 79$ to $>\$ 600$ and their qualities are of a comparable range. Patients and their partners should be encouraged to buy the best quality product that they can afford. ED, erectile dysfunction; VED, vacuum erection device.

with the sexual pleasure provided by the partner.

All ED treatments have the potential to be eroticized regardless of what the aid is. For example, Kukula et al. (16) presented a scenario where a partnered patient visits a clinician alone, wishing to try a PDE5i drug. In their scenario, the patient is advised by his clinician to come back for a consult with his partner before being given the prescription. During that follow-up consultation, the clinician then asks the partner how he/she feels about the patient trying a PDE5i. If the partner is comfortable with the patient trying the drug, the clinician could then offer the prescription to the partner to fill, along with the counsel that the partner offer the patient a PDE5i pill, if "be is nice to you" (i.e., the patient courts the partner's attention).

In such a scenario, the ED treatment is explicitly linked to the partner and not just to the penile physiology of the patient. There is a potential for partner's involvement as well with injectable drugs and mechanical aids. For example, partners, if willing, can be trained to inflate an internal penile prosthesis and encouraged to include the inflation process as part of foreplay. Partners can also learn and offer to assist with using the VED or administering ICI for patients. Again, this process can be integrated into foreplay, where a willing partner not only approves the use of the aid, but also actively engages with the aid before and during sexual activity in a fashion that eroticizes the aid. Such eroticization can be accomplished best, if the partner is involved with treatment selection and displays enthusiasm for a treatment option from the beginning.

Similarly, if a clinician is encouraging a partnered patient to explore over-the-counter (or online) sex products, such as vibrators and lubricants, the patient should be strongly 
encouraged to shop with his partner. Elsewhere (16,35), we have discussed how involving partners in such activities can build intimacy in a broad sense, even when the aids do not restore full erection. This is predicated on the fact that intimacy can be considered as something a couple shares with each other and no one else (35). While penetrative sex may be considered archetypal intimate act, a simple activity of shopping together for sex aids is still an intimate act that can thus strengthen co-supportive spousal/partner bonds.

Unfortunately, sexual dysfunction is a complex issue and many men simply do not seek help when faced with ED. In one study, only $30 \%$ out of 510 men diagnosed with ED sought treatment (53). Patients may also acquire sexual aids privately and use them covertly. Fear of being found using a sex aid surreptitiously may contribute to the drop-off in their use (16). Some men may rationalize that using the aids without engaging their partner shields them from being seen by their partner as sexually inadequate. They may also try to avoid feeling shamed, should their partner find out that they use an aid for achieving an erection. However, secrecy undermines trust. Part of the decline in the use of otherwise effective ED treatments may be because the men perceive the aid not as empowering (i.e., providing potency in a broad sense), but rather reaffirming their disability; i.e., heightening their awareness of their impotence (in a narrower sense) and thus making them feel emasculated (34).

Another possible reason men, who started using physiologically effective aids secretly, stop using them is they become weary of the deception as they come to recognize that clandestine activities can damage good relationships, which depend on openness and honesty. This argument can be extended to helping men with ED, who are unpartnered, but hope to start a new relationship. Men in that situation should be encouraged to be open and honest about their ED and use of ED aids early when they are developing a new partnership. Honesty wins respect, whereas late discovery of ED treatment use can lead new partners to question the patients' overall trustworthiness, making development of cosupportive relationships more challenging.

\section{Non-pharmacological and non-surgical options for sexual recovery}

When ED treatments are not effective or acceptable, patients are often encouraged to explore sexual practices that are not erection-dependent, such as oral sex and mutual masturbation. When sex therapy options are categorized that way, they could be considered as "gendered", following a conventional gender binary. The masculine approach focuses on regaining erections, whereas the feminine approach is to accept sexual practices that do not require penile penetration (35). When so dichotomized, the aids for sexual recovery noted below may be categorized better as "post-gendered" (54). Use of certain appliances, such as an external penile prosthesis, falls outside of a strict male/ female dichotomy of sex roles in that it does not rely on the recovery of erections itself (the masculine role), yet does not force a couple to abandon penetrative sex and accept nonpenetrative sexual practices (the feminine role). Instead, this approach involves a man-prosthetic coupling-a cyborgian solution (55).

We believe that patients burdened by severe ED should be informed about the existence of such options before acquiescing to the idea that penile implants are their only option. Being aware of such non-medical options is part of making an informed decision about medical interventions. Within the model for clinical care, where patients progress from least to most invasive treatments, patients and their partners should be at least educated about the pros and cons of these options, along with being counseled about surgical implants. The willingness of patients with intractable ED to explore non-surgical interventions may depend not only on them (and their partners) being aware of the options, but also on whether they are encouraged by their healthcare providers to explore these options in an objective fashion. In the following sections, we review some of these non-surgical and nonpharmacological options. Table 1 presents some information on the demographics of men who use some of these aids and the cost of representative products in various categories.

\section{External penile prostheses}

The number of sexual health clinicians, who advise patients about external penile prostheses (Figure $1 A$ ) as an alternative to ED treatments, is not known. Anecdotally though, it seems uncommon for urologists to suggest to patients to first try an external prosthesis when counseling them about penile implants. This is despite the medical dictum to try less invasive treatments before moving on to more invasive ones.

Many factors could account for why this non-invasive option gets little attention by healthcare providers.

\section{The names for the external prostheses may be unappealing}

An "external prosthesis", when attached to pelvic harness, has the common name of a "strap-on dildo" (see Figure 1A). 
For many people that name connotes a vulgarity. Such sexual aids have historically been marketed predominantly to lesbians starting back when same-sex sexual practices were not socially acceptable $(56,57)$ and the stores selling the products were in less desirable neighborhoods. That, however, is changing rapidly. Sexual products, such as lubricants, are now openly available in drug stores, and dildos are readily available for purchase from many online retailers, including Amazon.com.

Gray and Klotz (28) suggest that patients' willingness to try such an aid would be enhanced if the aid was "medicalized", i.e., formally endorsed or recommended by healthcare providers in a clinical setting. As a step in that direction, Gray and Klotz rebranded the strap-on prosthesis with the more erudite sounding name, "belted prosthetic phallus". However, an internet search for this neologism showed that that name has failed to gain any traction in the public or medical domains.

Warkentin et al. (29) believed, in contrast, that for the use of such an aid to be effective, it had to be truly in the realm of sexual play and not medicalized. Notably, the products are sold as "sex toys" and not as medical appliances. There are no known studies exploring whether patients and their partners are more or less willing to try this option, or whether they find it more effective, if medically prescribed versus promoted as a sex toy.

\section{The products have not been well-tested or promoted in the medical literature}

What has been published to date on external penile prostheses are case studies and anecdotal reports $(28,29,58,59)$. There is a need for research to identify which patients (and partners) are likely to try this option and which ones find it effective in restoring satisfying sexual activity. Based on the narrative in Warkentin et al. (29), in order to be effective both the patient and his partner need to be adventurous enough to explore novel sex practices when the patient is confronted with ED. Couples should understand that this pathway to sexual recovery circumvents any need to recover erections. Furthermore, use of such a prosthesis means that the couple can be confident that the prosthesis will always remain firm so penetrative sex is possible despite ED.

\section{Healthcare providers may be unaware of how using an external penile prosthesis can lead to rewarding sex}

Both healthcare providers and patients may either not consider or summarily dismiss an external prosthesis as a pathway for sexual recovery. It may not be obvious to them that having intercourse with an external prosthesis could still be sexually satisfying for a couple, even if it is not his penis that penetrates his partner. However, case reports $(28,29)$ indicate that an external prosthesis, when incorporated in penetrative sex, may recreate the sensory experience of coital sex without the patient needing the penile rigidity for intercourse.

Dismissal of this option could be because of a lack of knowledge about how couples can use an external prosthesis in coital sex to lead to sexual gratification including orgasm for both partners. As discussed in a case report of a heterosexual couple by Warkentin et al. (29), the partner can provide manual stimulation directly to the patient's penis while prosthesis-vaginal coupling takes place. The patient in that study felt that his coital posture and body movements were identical to when he had previously experienced during penile-vaginal intercourse. Warkentin et al. further argued that his experience constituted a version of the "rubber hand illusion" as described below-but, of course, it is not an artificial hand, but an artificial penis that is now involved in the sensory illusion.

\section{The neurophysiology of the rubber hand illusion is not well understood}

Warkentin et al. (29) and Wassersug (35) offer a neurophysiological mechanism for how using an external penile prosthesis may lead to rewarding orgasmic sex for men with ED. They suggested that such an experience is a variant of the rubber-hand illusion where, in the original model, a person perceives a fake rubber hand as part of their own body $(60,61)$. In that experience, a rubber hand is juxtaposed to one's real hand, but the real hand is kept hidden from the person's view. When the fake and real hands are touched simultaneously, the person integrates the visual and tactile information, and perceives the fake hand as their own (62). Ehrsson and his colleagues (63) have further shown that multisensory integration can occur with tactile-tactile stimulation, which does not require visual input. Warkentin et al. (29) suggest that a comparable illusion may occur when a man is having intercourse using an external penile prosthesis. Though the prosthesis rather than the man's penis is the one penetrating his partner, he may perceive the prosthesis as his own penis and, if sufficient sexual arousal is achieved, an orgasm may occur for him, and possibly for his partner too. 
Although orgasms are understood to be predominantly the product of direct haptic stimulation to erogenous tissues (64), there is typically much more stimulation that occurs during penile-vaginal intercourse. During that activity, the couple's torsos can be in alignment with each other, providing whole body tactile stimulation (65). Their heads can be in close proximity, such that there can be a wealth of visual, olfactory, and acoustical stimuli during coitus, which can be integrated in the brain with erogenous tactile stimuli to intensify sexual arousal. There can as well be reciprocal arousal as each partner's responses to the other.

In all multi-sensory integrated events, the brain concurrently compiles several sensory inputs to produce a single coherent perception [see refs $(63,66)$ as summarized in https://en.wikipedia.org/wiki/Multisensory_integration]. Fulfilling sexual experiences that include multi-sensory stimuli, which culminate in the singularity of an orgasm, fit the criteria of such integrated events (67). Much has been written previously about multi-sensory integration, although research that explicitly explores orgasms in that context is difficult to find.

A region of the brain which may contribute to multisensory integration is the claustrum (68). Many neurons in the claustrum have reciprocal projection to almost the entire brain (69-72). Such neuronal networks make the claustrum an ideal area for widespread neuronal transmission for both somatic and special sensory input integration. Furthermore, the claustrum is also activated during sexual activity (73-77), although its precise role in orgasm is not fully established (78).

For men who are adventurous and attuned to the totality of sensory stimulation during sex, the sensory experience achieved during intercourse with an external penile prosthesis may closely match the sensory experience of normal coitus and lead to orgasm. Use of the prosthesis can empower patients who accept the prosthesis as part of themselves, much the same way that well-adapted wheelchair dependent patients come to accept their chair as an extension of who they are $(55,59,79)$.

In using the external prosthesis, fear from the patient about not getting or sustaining an erection during sex is muted, and apprehension about whether an ED treatment will be fully effective is avoided. Often men are encouraged to accept non-coital sexual practices, such as oral sex and mutual masturbation, when their erections are not firm enough for penetrative sex. The use of the external prosthesis is likely to be equally effective to these strategies for sexual recovery in that it allows for the embrace and full body contact that are experienced during copulation.

\section{Physicians do not receive commercial incentive for promoting external penile prostheses or other over-the counter solutions for sexual recovery}

This is true as these are over-the-counter products and healthcare providers make no profit in recommending them to patients. Furthermore, such sexual aids are not typically covered by medical insurance. From the patient's perspective, though, the current cost of a good harness and dildo is equivalent to approximately 1.5 months supply of generic tadalafil. Thus, over time the cost for such aids would be more economical than pharmacological ED treatments.

\section{Healthcare providers may be unfamiliar with or unaware of external penile prostheses}

The options for an external penile prosthesis on the market are extensive, which may make choosing the "best" prosthesis challenging. Many dildos and harnesses are flashy and come in various size, color, and shape. Some people may see such embellished objects as unappealing as they imply that the manufacturers give primacy to tacky flamboyance. Furthermore, rarely do these objects closely match a particular individual's erect penis in terms of size, shape, and color. However, getting a dildo that does match a man's erectile penile morphology is possible, for example, by using products that allow a man to make a direct casting of his own erect penis (assuming he still has normal erections or can achieve one with medical assistance). Information on these casting products sold to the public can be found, for examples, at: http://cloneawilly.com; http:// www.copymekits.com and http://www.createamate.com.

As for the harnesses, there is at least one product on the market made specifically for men; i.e., the Deuce from SpareParts (https://www.myspare.com/product/deuce), which emphasizes functionality over ornamentation. Positive reviews, while anonymous and anecdotal, on this product can be found on Amazon.com (e.g., https://www. amazon.com/gp/customer-reviews/RAMX4OZCB7TMZ/). These reviews include an account from a man, who, like the patient in the Warkentin et al. study (29), claimed to reach an orgasm when wearing prosthesis for vaginal penetration. Another product, the Zoro or Armour Knight (PerfectFitBrand.com) has the phallus incorporated into the harness. These are less expensive than buying a separate 
harness and dildo, but the dildo cannot be personalized.

A lack of familiarity with such products, or with men who have used them effectively, may lead some healthcare providers to assume that they are not effective. However, there are patients who acquire such products and find them very effective, but remain discreet. As such, they may never come to the attention of healthcare system. It remains an open question as to how common and effective such nonmedical interventions for sexual recovery are for men afflicted with ED.

\section{Penis sleeves, extenders and penile support devices}

There is a range of over-the-counter products that can cover the penile shaft and permit insertive sex even when the unaided penis alone is not firm enough for penetration or to sustain coitus to orgasm (Figure 1, Table 1). Some sleeves are essentially hollow dildos with space inside for the penis. Some can be attached to a harness and thus, resemble the external penile prosthesis just described. Others cover just the penile shaft with an opening at the end to expose the glans and/or have numerous surface protrusions to enhance stimulation. Some are coupled to a vibrator. Currently, it is not known if the addition of a vibrator helps patients with ED or their partners achieve orgasms; however, penile vibrostimulation can help men with spinal cord injury ejaculate [although the vibrating stimulus for ejaculation in spinal cord injured patients is typically more intense than the one incorporated in penile sleeve; (80)]. Notably, a vibrator attached to the penile sleeve (or otherwise) may provide tactile stimulation for both the patient and his partner $(81,82)$.

There is one medical-grade vibrator with adjustable frequency and intensity that is marketed for patients with ED, the Viberect (83). Other vibrators (e.g., Cobra Libre from funfactory.com or Pulse from hotoctopuss.com) can also be used as masturbatory aids. However, these products are not designed to be used in conjunction with penetrative sex. The latter two, though, can be used as a stimulatory aid between a couple, i.e., the patient's penis is inserted into the device while the device is directly placed on his partner's genital. Suffice it to say, these vibrators have not been shown to be more effective for men than less expensive vibrators on the market.

On one hand, penis sleeves may seem better than external penile prostheses because they allow the penis to retain an insertive role. However, the effectiveness of penile sleeves may vary greatly depending on a variety of physical features (e.g., their size, shape, thickness, vibrator capability), plus their use in insertive versus masturbatory sex. Sexual arousal and reward per se depend on a variety of biological factors that are situational-dependent. These include a man's limerence, amount of residual erectile capacity, and reciprocal feedback from his partner (in the case of partnered sex). The amount of tumescence, in turn, can influence how much the penis moves within and in relation to the inner wall of a sleeve, and thus how much tactile stimulation the penis receives. The luminal size of the sleeve may play an important part in the tactile stimulation to the patient's penis. With severe ED, the penile shaft and glans may not come in full contact with the wall of the sleeve, and thus limit tactile stimulation. Patients interested in trying such a device need to find the product with the right luminal size for them. At least one company (RxSleeve-www.rxsleeve.com; Figure 1B, Table 1) markets a product that provides customizable size.

Since the effectiveness of penile sleeves depends on factors beyond the products themselves, patients (and, again, partners) should be encouraged to explore the diversity of what is available in stores, online, or within a sexual health clinic. Couples should also be encouraged to decide together on which device they would like to try. As with most sexual aids, clinicians and patients alike should recognize that a product that works well for one couple may not work well for another. In the clinical setting, discussing the pros and cons of various options ideally requires having a diversity of products on display and clinicians who can talk objectively about the products.

Penis extenders may improve penile length, help treat Peyronie's disease, and can be effective as an adjuvant to penile implants for increasing penile length. They are thus commonly prescribed for penile traction therapy and their merits in that regard are reviewed by Trost et al. (84).

A penile support device, such as the Elator (www. TheElator.com, Figure 1C, Table 1), can be used as a wearable support device in penetrative sex. The device braces the penis's shaft, while pulling the glans away from the base of the penis. An instructional video on how to use the Elator can be found on: www.youtube.com/ watch?v=AokWVYxpzY4. Penile support devices are not dependent on residual erections and may provide direct tactile contact between the patient's penis and his partner's vaginal or anal mucosa. Published data on the effectiveness 
of these aids in helping couples have satisfactory coitus or achieve orgasms are lacking.

\section{The vacuum erection device and the hinge effect}

The VED is typically the first non-pharmacological option offered to patients with ED (85). Several major reviews have endorsed the VED for ED management $(84,86,87)$ and have concluded that, quoting Trost et al. (84), "the VED is effective in creating an erection satisfactory for intercourse". This is backed by data showing that both sexual and marital satisfaction for patient with ED and their partner is higher for those who use the VED.

However, the enthusiasm for the VED must be tempered by a few facts. Although the VED is often touted as an aid to accelerated recovery of erections, the VED's effectiveness in that regard is not strongly supported by studies to date $(84,88)$. A more serious concern is poor long-term compliance. For example, in one study of 141 patients offered different non-oral ED treatments after prostatectomy (89), only 39\% at one year remained sexually active using VED and only 5\% continued with the VED at the five-year mark. Similarly, Baniel et al. (90) reported that in a sample of 85 men, $92 \%$ found the VED effective in restoring erection firm enough for vaginal penetration, but only $14 \%$ continued to use the VED at home. Such data suggest that erections achieved with the VED may be firm enough for intercourse, but the experience of using the VED and/or the erections it produces are not ideal for sexual intercourse.

The VED has an unaddressed weakness. The problem begins with the fact that the VED fails to engorge the penile root within the perineum, leading to "hinging" of the shaft of the penis on the body wall $(84,91,92)$. During a full erection, the crura of the corpus cavernosa within the penile root and the corpora in the shaft are not in a straight line, but rather are boomerang-shaped in the sagittal plane (65); see video at: www.youtube.com/watch? $v=1 \mathrm{~J} 4 \mathrm{Mfj}$ _W9sY), with the shaft turned upward in relation to the root. With a full erection, a good angle for penile-vaginal coitus is achieved. An orientation of the shaft that is too low (93) [or, for that matter too high; (94)] may affect penetration and require postural adjustment to sustain coitus to climax.

Although the VED can make the shaft of the penis longer, wider, and firmer than a flaccid penis, with hinging the erect penis points downward rather than upward and can pivot easily on a patient's torso. As a result of this hinging, an erection achieved with a VED does not maintain the properly erect orientation. A hinged "erection" can be inserted into a vagina (or, if firm enough, the anus with some manual assistance), but is at risk of not staying within the orifice during normal pelvic thrusting. Since the motion of the penile shaft in relation to the orientation of the vagina is not strictly linear (Figure 2), the thrusting motion is not purely a uniaxial in-and-out motion (65).

With a full erection, the shaft of the penis can easily be rotated upward in the vertical plane, but downward deflection is resisted by the suspensory ligament.* With a full erection, such as that shown by the MRI images of Figure 2, the range of rotations in the sagittal plane during a normal thrusting cycle is through some $15^{\circ}$ and may be even larger when the couple are not confined in an MRI machine or in a different sex position [Figure 2; (65)]. During coitus performed as in Figure 2, the firmness of the penis and its resistance to downward deflection by the suspensory ligament causes the shaft of the penis to compress the clitoris in rhythmic fashion against the overlying pubic symphysis. As shown in Schultz et al. [(65); see also www.youtube.com/watch?v=1J4Mfj_W9sY, Figure 2], this non-linear motion of the penis exerts pressure on the anterior wall of the vagina, providing stimulation to the whole clitourethrovaginal complex (95). This stimulatory pattern can synchronize and coordinate arousal between the partners.

In penile/vaginal intercourse, the way the penis moves in relation to the vagina can be critical to the degree of fulfillment for both partners. Penile-vaginal intercourse involves more extensive whole body sensory experience than solo masturbation. Although controversial, there are published claims that sexual satisfaction and function is better for females when achieved through penile-vaginal intercourse than through masturbation (96-98). This

\footnotetext{
* Many dildos on the market have a flared base that allows them to be held in place in a harness so that they can be used as a hands-free prosthesis. We know of no dildos designed to rotate upward easily yet resist downward rotation; i.e., mimicking the function of the suspensory ligament in the body. However, since these prostheses never become flaccid, the absence of this differential capacity for rotation may be less of a mechanical limitation for the prosthesis than for the actual penis.
} 

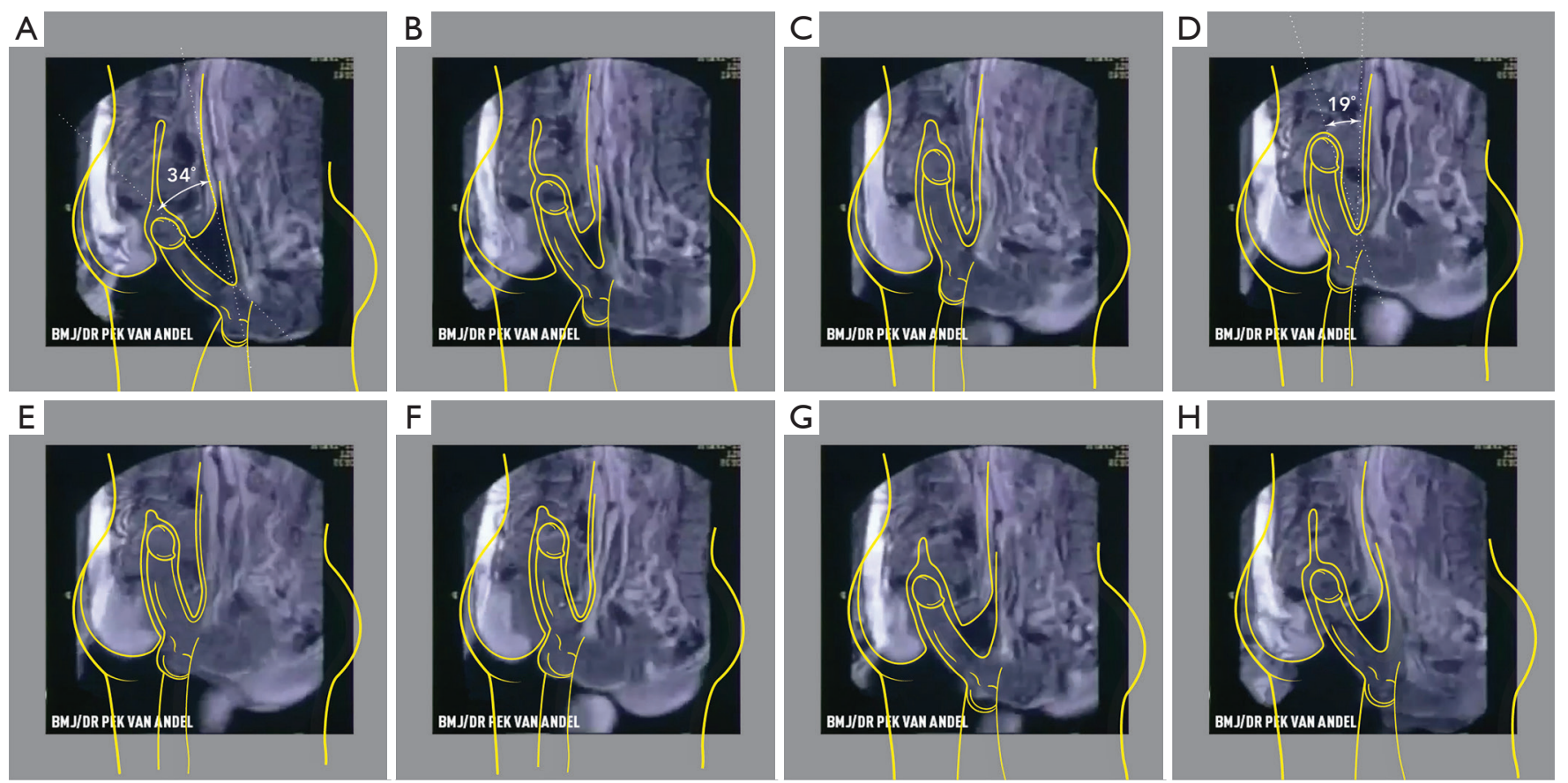

Figure 2 The complex kinematics of the penis during a single thrusting cycle of penile-vaginal coitus with the couple facing each other. The images are taken from the video publicly available at www.youtube.com/watch?v=1J4Mfj_W9sY, where a couple had intercourse in a MRI machine (65). The complete cycle shown here lasts for $1.6 \mathrm{sec}$, with the eight images in the series each separated by $200 \mathrm{~ms}$. The images confirm that the movements of the penis is not uniaxial, but rotates minimally up and down through $15^{\circ}$ in the sagittal plane (compare frames A and D) with each thrusting cycle. When the male has a full erection, downward rotation is resisted by the natural upward curvature of the penis shaft in relation to the roots of the penis, as well as by the suspensory ligament of the penis. When the penis is hinged and thus not oriented upward, the normal kinematics is impaired and can distract from the naturalness of the coitus (see text). This, in turn, can lead to a less than fulfilling experience for one or both of the partners, even if orgasm is achieved. The penile kinematics demonstrated here may differ if the couple have sex in some other position, in a less confined space, or are of different overall body size. Penile kinematics during penile-anal sex has not been explored.

could partially be because the stimulation during solo masturbation focuses mostly on the genitalia, whereas during intercourse there is much more non-genital, sensory input (e.g., from the embrace, torso alignment, visual contact, proximity of the couple's heads, etc.). The amount of extra erogenous stimulation may thus account for the coital sex being perceived of as more fulfilling than alternative sexual practices, such as masturbation or oral sex, regardless of how well the clitourethrovaginal complex is stimulated.

With hinged erections, effort is required from one or both partner(s) to compensate for loss of thrusting pressure on the clitourethrovaginal complex. For example, there is often an increase in the amplitude of the man's rostral movements in relation to his partner as orgasm is approached. But with his more extensive upward movement, the hinged penis is more likely to deflect downward, increasing the chance of penile-vaginal separation if the hinging is severe. Rhythmic stimulation from the penis to the clitourethrovaginal complex will thus be compromised with hinged erections. Such impairment may affect the ability of both partners to reach an orgasm and decrease the chances of synchronized arousal (if not orgasm) between the partners. Should the penis slide out of the vagina - or is sensed as a possible risk when arousal is high and orgasm is approaching-the unanticipated disruption can generate anxiety and frustration for one or both partners, eroding their sexual confidence. It should be noted that the female partners of patients using the VED report lower rates of sexual satisfaction than do the patients themselves (84), possibly because stimulation to the clitourethrovaginal complex is hampered when the erection 
is hinged. Furthermore, the problem is not unique to VEDacquired erections. All partial erections are characterized by some hinging because a penis acquires its full and proper orientation only with full engorgement of the cavernous tissue. It is, thus, not surprising that patients often abandon efforts at intercourse when ED treatments only restore partial erections.

Heterosexual couples may be able to make postural adjustments to avoid disruption of intercourse and subsequent disappointment, when hinging exists. One possible adaptation is for the female to be on top, because in such a position the female can better control the movement of the penis in her vagina.

Neither the biomechanics of coitus nor the psychological distress that can emerge when penile kinematics is affected by hinging has been adequately investigated (99). From the limited information at hand, any partial solution to ED that produces an erection operationally "hard enough for penetration" (i.e., yielding a high International Index of Erectile Function, IIEF, score, (100) yet hinged, may lead to a less than fully satisfying experience. Failure of the penis to perform normally and naturally during coitus may lead to one and/or the other partner feeling that they have somehow failed, degrading the experience for both. Often one or both partners may sense that their sexual encounter was not quite right, but do not understand why.

The literature on ED directed at patients understates the extent of the hinging problem. In the most popular book on the ED for prostate cancer patients [i.e., Saving your sex life: A guide for men with prostate cancer; (101)], the hinge effect is barely mentioned and not flagged as a potential distraction from the naturalness of coital sex. In a more recent Mulhall and Jenkins article (102), there is a single sentence acknowledging the hinge effect followed by the statement that with erections from the VED "it may be necessary to direct the penis for penetration". What is not discussed in that article is the fact that in coitus, penile kinematics are not simply linear and it is the hips, not the hands, that direct penile kinematics.

The marketing materials for VEDs neither mention the hinge effect nor postural adjustments to compensate for it. It is unknown how often healthcare providers, who recommend a VED to patients, inform the patients and their partners about the hinge effect nor how to limit the chances of it disrupting coitus. Minimally, patients and their partners being offered the VED should be informed about the hinge effect and how to adapt to it.

\section{The psychological costs of ED treatments that are not fully effective}

As noted above, the long-term adherence to the use of the VED as a treatment for ED remains poor (84). Any ED treatments that are partially effective can dishearten both patients and their partners in the long term because the intercourse experience no longer feels satisfactory. This may account in part for why so many ED treatments that are physiologically effective are nevertheless abandoned after a period of time despite residual ED. They reflect discordance between the quantitative nature of assessment indices, such as the IIEF, and the psychological reality of good sex. Furthermore, a recognized problem with all ED treatments is that their use takes planning, with a consequent loss in spontaneity. Developing an erotic association between the aids and patients' sexual partners may help override this problem. Such erotization converts the barrier to sex aid use into a benefit by making the preparatory activity part of foreplay.

From the perspective of the IIEF-5, an ED treatment that raises a prostate cancer patient's score from, say, 10 after a prostatectomy to 16 can be considered a clinically significant improvement. But if the patient's IIEF-5 score was 20 before his prostatectomy, the comparative decrease of his sexual performance before his ED may still be experienced as a loss. He may not view a rise from 10 to 16 as triumphant, but rather sense his current coital capacity as a reduction from the IIEF score of 20 he previously had.

Numbers similar to these have, in fact, been reported for patients using the VED. As an example, Nason et al. (86) studied 65 men (mean age 57.6), who had iatrogenic ED from a prostatectomy. Before their surgery the men's mean IIEF-5 score was 22, but that declined to 11.3 in the three months post-surgery. VED use was initiated and raised the mean IIEF-5 score to 16.7 . This was a clinical and statistical significant increase of $48 \%$, but the mean score of 16.7 can also be viewed as a decrease of $24 \%$ from the patients' mean baseline score of 22 before ED. Each time a patient uses the VED it may remind him of his loss, of his disability. Overtime, he may gradually avoid coital sex all together to reduce any further sense of failure that erodes his confidence and quality of life.

A withdrawal from coital sex may, in turn, be interpreted by his partner as disinterest in their relationship, sexual or otherwise. The partner may feel that they were somehow 
complicit in his withdrawal from sex, and that they, the partner, had lost their erotic allure. That may negatively impact the partner's self-esteem. In sum, sub-optimal ED treatments carry the risk of deteriorating rather than strengthening dyadic bonds.

\section{Is a pre-habilitative approach to sexual recovery possible?}

A growing concept in cancer care is pre-habilitation $(103,104)$, which has historically been associated with improving patients' physical status before undergoing elective surgical procedures, such as knee and hip replacements or coronary artery bypass surgery. Silver and Baima (103) describe prehabilitation as a "... a process on the continuum of care that occurs between the time of a cancer diagnosis and the beginning of acute treatment...." They envision prehabilitation as providing "targeted interventions that improve a patient's health to reduce the incidence and the severity of current and future impairments."

In oncology, pre-habilitative exercises have primarily been promoted as an intervention to reduce the overall deconditioning associated with oncological treatments, such as for breast, lung, and colorectal cancers (103). For prostate cancer patients, prehabilitation has been explored in two regards: pre-operative stress management to improve post-operative immune function (105) and pre-operative physical exercise to improve a range of post-operative parameters, from length of hospital stay (106) to overall exercise capacity and quality of life (107).

In terms of pre-habilitative approaches to sexual recovery, individual and group educational sessions are available for men undergoing a primary treatment for prostate cancer (108-112). These programs are typically designed to educate patient and family members about the side effects of treatment with a common goal of reducing treatment decision regret and the psychological burden from impaired sexual and urinary function. These programs have had only limited success and long-term outcome data are few.

Part of the problem is that many men who undergo primary prostate cancer treatments have an unrealistic expectation about their odds of adverse effects from treatment. Wittmann et al. (113) found, for example, that with a sample of over 150 patients, almost half of the men attained worse than expected urinary continence and sexual function after a prostatectomy despite pre-operative counseling. Against this background, it may be that a pre-habilitative approach to recovery of erection has the potential to improve patients' willingness to both start and stay with a penile rehabilitiation after a prostatectomy.

The type of pre-habilitative program we suggest would offer patients a chance to have a test run at an ED treatment, such as ICI, to create a full erection before their prostatectomy. In that way, patients would witness the effectiveness of ICI and potentially be more willing to use ICI, if they had ED subsequent to a prostatectomy. Furthermore, if the patients so wished, they could in that same ICI session have a casting made of their erect penis that could then be used to produce a personalized external penile prosthesis that matched their normal erect penile morphology. This could in turn be used as an external penile prosthesis as described above.

If partners are comfortable with the program, we would encourage their involvement in sexual pre-habilitation, just as we did for sexual rehabilitation. If willing, partners could be taught how to help in using the VED, how to do ICI, and even assist with the penile casting. This could help build an erotic association of the partner with the aid in advance of any ED. Admittedly, the number of patients and partners who would be willing to participate in such sexual "pre-habilitative" programs is not known. Psychosocial research in this regard is warranted.

\section{The relevance of IIEF for men in the context non-erection dependent sex}

This review of non-pharmacological and non-surgical options for men with ED raises several issues worthy of further attention, starting with the limitations of the IIEF5 , and what it can and cannot tell us. For assessing erectile function, the IIEF-5 is popular for its simplicity $(100,114)$, providing a single number as a measure of ED. When used to assess recovery of sexual function after a prostatectomy, it presumes, if not endorses, a phallocentric perspective, which gives primacy to erections (mainly for penetration purposes) as the sine qua non of good sex for males. That is consistent with a recent review of more than 40 studies addressing the impact of prostate cancer treatments on men's masculine identity and self-esteem (34). In that study, having erections was identified as the dominant (i.e., definitional) male trait. There is no question that having ED reduces men's quality of life $(4,7)$. However, the high attrition rate for all physiologically and mechanically effective ED treatments suggests that penile tumescence alone does not assure a man a good and prolonged sex life (26).

The scoring of the IIEF-5 is not balanced in that the 
first four questions deal specifically with penile tumescence. The last question is different in that it asks how satisfying intercourse is. One might expect that 'satisfaction' would outweigh the other questions in term of sexual recovery, but the IIEF-5 is not scored that way. One problem is that satisfying sex for a male may or may not involve being the insertive partner in intercourse and, thus, an erection is not always essential, making the IIEF score irrelevant in some cases. This point has already been raised in discussions about sexual practices for non-heterosexual men (115-119).

Indeed, many manage to find rewarding orgasmic sex even with chronic ED. Survey data from 558 prostate cancer patients provided insights into how both heterosexual and non-heterosexual men's sexual practices can change as a result of their prostate cancer treatments $(27,120)$. At one extreme, many men asserted that their "sex life was over" as a result of iatrogenic ED. At the other extreme, some had elected penile implants and were satisfied with the outcome. What was interesting, though, was the diversity of novel practices and options between those extremes. Data from 348 of the men (27) confirmed that it was possible for many men to reframe their sexual practices, and that having a supportive sex partner was of major importance for many in exploring new sexual practices.

In those studies $(27,120)$, men's sexual practices were diverse and included using various non-surgical sex aids (dildos, vibrators, etc.) in both solo and partnered sex. Some of these aids allowed the men to continue to practice penile-insertive sex, even if they had only partial erections. Other men found end runs around ED treatments, such as the use of an external penile prosthesis, which required no erection at all yet still permitted insertive partnered sex. Lastly some men, both homosexual and heterosexual men, shifted their practices to incorporate receptive anal sex into their sexual repertoire (27).

What remains unknown is how often such novel sexual practices are explored and taken up by men with ED. Presumably, they are more common among nonheterosexual than heterosexual men simply because nonheterosexual men are more likely to use vibrators and possibly other sex toys, than heterosexual men $(121,122)$. What factors contribute to the openness of men, who normally take the insertive role, to explore the receptive role is uninvestigated.

\section{Discussion}

For these novel practices to have a realistic chance of providing sustained benefit to partnered patients, the partners' support of the practices is likely essential. This brings us back to the importance of engaging partners early in sexual recovery. As mentioned earlier, emphasizing the importance of partner involvement has been addressed in several recent reviews $(15,31,35,123)$. Kukula et al. (16) suggest that engaging partners in all aspects of sexual recovery, especially in aid selection, may help eroticize the aid and should, in theory, reduce attrition. If this hypothesis is correct, it should apply to all sexual aids, be they wellestablished interventions, such as penile implants, or overthe-counter devices marketed as sex toys.

Randomized controlled trials to assess the importance of early partner engagement in improving long-term adherence to ED treatments have yet to be executed. Acquiring data to assess the importance of partners in the long-term compliance with sexual aids is one of a series of research questions that emerge from this review. Likewise, the acceptability and effectiveness of external penile prostheses and other sex toys, which are not strictly ED treatments, also need objective assessments. There are indeed many outstanding questions, such as:

\section{What characterizes patients and partners, who are most willing to try non-pharmacological and non-surgical options for sexual recovery after iatrogenic ED?}

Undoubtedly, how open patients and partners are to trying non-surgical options vary. Even in a strong co-supportive couple, the patient and partner may have a different opinion about experimenting with new sex aids and devices. It would be useful to develop a survey tool that can predict which patients and partners are most willing to try nonpharmacological and non-surgical options when faced with ED. Such a tool could also be used to assess who benefits most from those sexual aids.

Furthermore, which patients are willing to try an external penile prosthesis are not known. Within the pre-habilitative model, educating couples before a man undergoes a medical treatment that leads to iatrogenic ED, might bolster their willingness to try and adhere with various sexual aids. During the pre-treatment session, patients could be offered a chance to make a cast of their erect penises, so that they can have personalized external prostheses. Currently, it is still unclear which patients would be willing to participate in such a procedure and benefit in the long-term by acquiring a personalized phallus before they are afflicted with ED. 
What characterizes patients who are willing to try ICI before a prostatectomy?

The attrition rate from ICI remains high, and some reasons for withdrawal include pain, loss of libido, fear of self-injection, and ineffectiveness of the treatment (20,124-126). However, to avoid drop-out when the treatment is physiologically effective and seemingly welltolerated at the outset, more research is warranted to predict which patients are likely to have the best long term compliance. A study of that kind could include a test run of ICI (i.e., a voluntary pre-habilitative exposure) before patients undergo medical treatments with a high incidence of iatrogenic ED, such as a prostatectomy. Such a study could reveal the characteristics of patients, who are most willing to participate in a pre-habilitative program, and help determine if a pre-habilitative approach to ED treatments increases adherence to effective ICI protocols.

\section{Does engaging the partner in selecting ED treatments correlate with the couple's long-term use of the treatment?}

As we noted above, several papers have mentioned the potential benefit in involving partners throughout the trajectory of ED management, including treatment selection $(15,16,31)$. It may be important for couples to select a treatment that they are both open to trying, but this has not been investigated. Such a study would help determine how important partner's engagement is for long-term compliance. Furthermore, the study could address whether the association (i.e., the eroticization) of ED treatments with the partner reduces attrition.

\section{Do patients' sexual recovery correlate with their actual long-term survival?}

Although ED treatments are undertaken to improve men's quality of life, it remains to be determined whether recovering sexual quality of life might also correlate with overall survival. Restoring one's sexual life is known to improve quality of life overall, but a future study could explore if being sexually active, despite ED, provides an actual survival benefit (48). Doing so would strengthen the case for men with iatrogenic ED being encouraged to enter sexual recovery programs that are not necessarily erection-dependent.

\section{Conclusions}

The standard modalities for treating ED include PDE5i drugs, ICI, and penile implants. This array of treatments focuses specifically on penile tumescence. There are a variety of other non-pharmacological and non-surgical options, though, which have received little attention in the medical literature, yet may provide options for rewarding sex even when erections cannot be fully restored. Since the efficacy of these options has not been established in clinical trials, it may appear that healthcare providers do not need to counsel patients on the availability and use of those devices. However, following the doctrine to try the least invasive interventions first, clinicians have some responsibility to bring the non-medical interventions to the attention of patients looking for ways to deal with ED.

ED treatments of a medical nature are provided to patients following the individualized patient-doctor model for patient care. This one-on-one model may not be ideal when dealing with sexual concerns of partnered men because the quality of the bond between a patient and his partner can be critical to the effectiveness of any sexual therapy the physician provides. The enthusiasm of a patient's partner for a particular treatment may influence the patient's long-term compliance with the treatment. An ED treatments or any other sexual aids should ideally be offered to the couple for it is not just the individual patient, but the patient and his partner who will determine the therapies' prolonged success.

\section{Acknowledgements}

We thank staff from the Elator, RxSleeve, SpareParts companies for providing the data summarized on Table 1; Suzanne Chambers, Gary Dowsett, Stacy Elliott, Diane Kelly and Debra Soh provided helpful feedback on drafts manuscript. We thank Shyronn Smardon for assistance in the graphic of the figures and Marc Abraham gave us permission to use screenshots of the original video used in Figure 2.

\section{Footnote}

Conflicts of Interest: The authors have no conflicts of interest to declare.

\section{References}

1. Lue TF, Giuliano F, Montorsi F, et al. Summary of the recommendations on sexual dysfunctions in men. J Sex Med 2004;1:6-23.

2. Hatzimouratidis K. Epidemiology of male sexual 
dysfunction. Am J Mens Health 2007;1:103-25.

3. McCabe MP, Sharlip ID, Lewis R, et al. Incidence and prevalence of sexual dysfunction in women and men: a consensus statement from the Fourth International Consultation on Sexual Medicine 2015. J Sex Med 2016;13:144-52.

4. McCabe MP, Althof SE. A systematic review of the psychosocial outcomes associated with erectile dysfunction: does the impact of erectile dysfunction extend beyond a man's inability to have sex? J Sex Med 2014;11:347-63.

5. Althof SE. Quality of life and erectile dysfunction. Urology 2002;59:803-10.

6. Cappelleri JC, Zou KH, Bushmakin AG, et al. Cumulative response curves to enhance interpretation of treatment differences on the Self-Esteem And Relationship questionnaire for men with erectile dysfunction. BJU Int 2013;111:E115-20.

7. Chambers SK, Chung E, Wittert G, et al. Erectile dysfunction, masculinity, and psychosocial outcomes: a review of the experiences of men after prostate cancer treatment. Transl Androl Urol 2017;6:60-8.

8. Benoot C, Saelaert M, Hannes K, et al. The sexual adjustment process of cancer patients and their partners: a qualitative evidence synthesis. Arch Sex Behav 2017;46:2059-83.

9. Huri HZ, Mat Sanusi ND, Razack AH, et al. Association of psychological factors, patients' knowledge, and management among patients with erectile dysfunction. Patient Prefer Adherence 2016;10:807-23.

10. Shamloul R, Ghanem H. Erectile dysfunction. Lancet 2013;381:153-65.

11. Bruzziches R, Francomano D, Gareri P, et al. An update on pharmacological treatment of erectile dysfunction with phosphodiesterase type 5 inhibitors. Expert Opin Pharmacother 2013;14:1333-44.

12. Chen L, Staubli SE, Schneider MP, et al. Phosphodiesterase 5 inhibitors for the treatment of erectile dysfunction: a trade-off network meta-analysis. Eur Urol 2015;68:674-80.

13. Salonia A, Adaikan G, Buvat J, et al. Sexual Rehabilitation After Treatment For Prostate CancerPart 2: Recommendations From the Fourth International Consultation for Sexual Medicine (ICSM 2015). J Sex Med 2017;14:297-315.

14. Jarow JP, Nana-Sinkam P, Sabbagh M, et al. Outcome analysis of goal directed therapy for impotence. J Urol 1996;155:1609-12.

15. Li H, Gao T, Wang R. The role of the sexual partner in managing erectile dysfunction. Nat Rev Urol 2016;13:168-77.

16. Kukula KC, Jackowich RA, Wassersug RJ. Eroticization as a factor influencing erectile dysfunction treatment effectiveness. Int J Impot Res 2014;26:1-6.

17. Sexton WJ, Benedict JF, Jarow JP. Comparison of longterm outcomes of penile prostheses and intracavernosal injection therapy. J Urol 1998;159:811-5.

18. Movsas TZ, Yechieli R, Movsas B, et al. Partner's perspective on long-term sexual dysfunction after prostate cancer treatment. Am J Clin Oncol 2016;39:276-9.

19. Lehmann K, Casella R, Blochlinger A, et al. Reasons for discontinuing intracavernous injection therapy with prostaglandin E1 (alprostadil). Urology 1999;53:397-400.

20. Polito M, d'Anzeo G, Conti A, et al. Erectile rehabilitation with intracavernous alprostadil after radical prostatectomy: refusal and dropout rates. BJU Int 2012;110:E954-7.

21. Corona G, Rastrelli G, Burri A, et al. First-generation phosphodiesterase type 5 inhibitors dropout: a comprehensive review and meta-analysis. Andrology 2016;4:1002-9.

22. Chung E, Van CT, Wilson I, et al. Penile prosthesis implantation for the treatment for male erectile dysfunction: clinical outcomes and lessons learnt after 955 procedures. World J Urol 2013;31:591-5.

23. Trost LW, Baum N, Hellstrom WJ. Managing the difficult penile prosthesis patient. J Sex Med 2013;10:893906; quiz 907.

24. Lewis RW, Witherington R. External vacuum therapy for erectile dysfunction: use and results. World J Urol 1997;15:78-82.

25. Cookson MS, Nadig PW. Long-term results with vacuum constriction device. J Urol 1993;149:290-4.

26. Althof SE. When an erection alone is not enough: biopsychosocial obstacles to lovemaking. Int J Impot Res 2002;14 Suppl 1:S99-S104.

27. Wassersug RJ, Westle A, Dowsett GW. Men's sexual and relational adaptations to erectile dysfunction after prostate cancer treatment. Int J Sex Health 2016;29:69-79.

28. Gray RE, Klotz LH. Restoring sexual function in prostate cancer patients: an innovative approach. Can J Urol 2004;11:2285-9.

29. Warkentin KM, Gray RE, Wassersug RJ. Restoration of satisfying sex for a castrated cancer patient with complete impotence: A case study. J Sex Marital Ther 2006;32:389-99.

30. Riley A. The role of the partner in erectile dysfunction and its treatment. Int J Impot Res 2002;14 Suppl 1:S105-9.

31. Dorey G. Partners' perspective of erectile dysfunction: 
literature review. Br J Nurs 2001;10:187-95.

32. Fode M, Serefoglu EC, Albersen M, et al. Sexuality following radical prostatectomy: is restoration of erectile function enough? Sex Med Rev 2017;5:110-9.

33. Fisher WA, Eardley I, McCabe M, et al. Erectile dysfunction (ED) is a shared sexual concern of couples I: couple conceptions of ED. J Sex Med 2009;6:2746-60.

34. Tsang V, Skead C, Palmer-Hague J, et al. Impact of prostate cancer treatments on men's sense of manhood: implications for understanding masculinity. submitted.

35. Wassersug RJ. Maintaining intimacy for prostate cancer patients on androgen deprivation therapy. Curr Opin Support Palliat Care 2016;10:55-65.

36. Lafaye A, Petit S, Richaud P, et al. Dyadic effects of coping strategies on emotional state and quality of life in prostate cancer patients and their spouses. Psychooncology 2014;23:797-803.

37. Chisholm KE, McCabe MP, Wootten AC, et al. Review: psychosocial interventions addressing sexual or relationship functioning in men with prostate cancer. J Sex Med 2012;9:1246-60.

38. Katz A. Counseling men with prostate cancer and their partners. Sex Relation Ther 2015;31:473-87.

39. Chambers SK, Schover L, Nielsen L, et al. Couple distress after localised prostate cancer. Support Care Cancer 2013;21:2967-76.

40. Wassersug RJ. Prostate cancer as a 'couple's disease'. Urol Nurs 2014;34:152-3.

41. Samplaski MK, Lo KC. Erectile dysfunction in the setting of prostate cancer. In: Lipshultz LI, Pastuszak AW, Goldstein AT et al., editors. Management of Sexual Dysfunction in Men and Women. New York: Springer; 2016:73-86.

42. McConkey R. Effect of erectile dysfunction following prostate cancer treatment. Nurs Stand 2015;30:38-44.

43. Sherer BA, Levine LA. Current management of erectile dysfunction in prostate cancer survivors. Curr Opin Urol 2014;24:401-6.

44. Wilson JM, Atkinson C, Hughes S. Management of erectile dysfunction in men treated with androgen deprivation therapy. Trends Urol Mens Health 2013;4:13-8.

45. Cheung AS, de Rooy C, Hoermann R, et al. Quality of life decrements in men with prostate cancer undergoing androgen deprivation therapy. Clin Endocrinol (Oxf) 2017;86:388-94.

46. Symes Y, Song L, Heineman RG, et al. Involvement in decision making and satisfaction with treatment among partners of patients with newly diagnosed localized prostate cancer. Oncol Nurs Forum 2015;42:672-9.

47. Orom H, Biddle C, Underwood W, 3rd, et al. What is a "good" treatment decision? Decisional control, knowledge, treatment decision making, and quality of life in men with clinically localized prostate cancer. Med Decis Making 2016;36:714-25.

48. Diamond LM, Huebner DM. Is good sex good for you? Rethinking sexuality and health. Soc Personal Psychol Compass 2012;6:54-69.

49. Bergman J, Gore JL, Saigal CS, et al. Partnership and outcomes in men with prostate cancer. Cancer 2009;115:4688-94.

50. Gore JL, Krupski T, Kwan L, et al. Partnership status influences quality of life in low-income, uninsured men with prostate cancer. Cancer 2005;104:191-8.

51. Kollberg KS, Wilderang U, Thorsteinsdottir T, et al. Psychological well-being and private and professional psychosocial support after prostate cancer surgery: a follow-up at 3, 12, and 24 months after surgery. Eur Urol Focus 2016;2:418-25.

52. Aizer AA, Chen MH, McCarthy EP, et al. Marital status and survival in patients with cancer. J Clin Oncol 2013;31:3869-76.

53. Hyde MK, Zajdlewicz L, Wootten AC, et al. Medical help-seeking for sexual concerns in prostate cancer survivors. Sexual Medicine 2016;4:e7-e17.

54. Haraway D. A cyborg manifesto: Science, technology, and socialist-feminism in the late twentieth century. Simians, Cyborgs and Women: The Reinvention of Nature. New York: Routledge; 1991:149-81.

55. Taylor AE. Embodying technology: A hermeneutic inquiry into corporeality and identity as manifested in a case of strap-on dildo use. Pittsburgh, PA, United States: Duquesne University; 2012.

56. Loe M. "Dildos in our Toolboxes" The production of sexuality at a pro-sex feminist sex toy store. Berkeley J Sociol 1998-1999;43:97-136.

57. Fahs B, Swank E. Adventures with the "Plastic Man": sex toys, compulsory heterosexuality, and the politics of women's sexual pleasure. Sex Cult 2013;17:666c-85.

58. Wibowo E, Wassersug RJ. Multiple orgasms in menwhat we know so far. Sex Med Rev 2016;4:136-48.

59. Wassersug RJ. Mastering emasculation. J Clin Oncol 2009;27:634-6.

60. Botvinick M, Cohen J. Rubber hands 'feel' touch that eyes see. Nature 1998;391:756.

61. Kalckert A, Ehrsson HH. The moving rubber hand illusion revisited: comparing movements and visuotactile 
stimulation to induce illusory ownership. Conscious Cogn 2014;26:117-32.

62. Ehrsson HH, Spence C, Passingham RE. That's my hand! Activity in premotor cortex reflects feeling of ownership of a limb. Science 2004;305:875-7.

63. Ehrsson HH, Holmes NP, Passingham RE. Touching a rubber hand: feeling of body ownership is associated with activity in multisensory brain areas. J Neurosci 2005;25:10564-73.

64. Komisaruk B, Beyer C, Whipple B. The science of orgasm. Baltimore: The John Hopkins University Press; 2006.

65. Schultz WW, van Andel P, Sabelis I, et al. Magnetic resonance imaging of male and female genitals during coitus and female sexual arousal. BMJ 1999;319:1596-600.

66. Stein BE, Stanford TR, Rowland BA. Development of multisensory integration from the perspective of the individual neuron. Nat Rev Neurosci 2014;15:520-35.

67. Safron A. What is orgasm? A model of sexual trance and climax via rhythmic entrainment. Socioaffect Neurosci Psychol 2016;6:31763.

68. Naghavi HR, Eriksson J, Larsson A, et al. The claustrum/ insula region integrates conceptually related sounds and pictures. Neurosci Lett 2007;422:77-80.

69. Tanne-Gariepy J, Boussaoud D, Rouiller EM. Projections of the claustrum to the primary motor, premotor, and prefrontal cortices in the macaque monkey. J Comp Neurol 2002;454:140-57.

70. Crick FC, Koch C. What is the function of the claustrum? Philos Trans R Soc Lond B Biol Sci 2005;360:1271-9.

71. Park S, Tyszka JM, Allman JM. The claustrum and insula in Microcebus murinus: a high resolution diffusion imaging study. Front Neuroanat 2012;6:21.

72. Smythies J, Edelstein L, Ramachandran V. Hypotheses relating to the function of the claustrum. Front Integr Neurosci 2012;6:53.

73. Georgiadis JR, Farrell MJ, Boessen R, et al. Dynamic subcortical blood flow during male sexual activity with ecological validity: a perfusion $\mathrm{fMRI}$ study. Neuroimage 2010;50:208-16.

74. Georgiadis JR, Reinders AA, Paans AM, et al. Men versus women on sexual brain function: prominent differences during tactile genital stimulation, but not during orgasm. Hum Brain Mapp 2009;30:3089-101.

75. Arnow BA, Desmond JE, Banner LL, et al. Brain activation and sexual arousal in healthy, heterosexual males. Brain 2002;125:1014-23.

76. Redoute J, Stoleru S, Gregoire MC, et al. Brain processing of visual sexual stimuli in human males. Hum Brain Mapp
2000;11:162-77.

77. Redoute J, Stoleru S, Pugeat M, et al. Brain processing of visual sexual stimuli in treated and untreated hypogonadal patients. Psychoneuroendocrinology 2005;30:461-82.

78. Stoleru S, Fonteille V, Cornelis C, et al. Functional neuroimaging studies of sexual arousal and orgasm in healthy men and women: a review and meta-analysis. Neurosci Biobehav Rev 2012;36:1481-509.

79. Pukall CF, Wassersug RJ. The parts, the pieces, and how they respond. In: Pukall CF, editor. Human Sexuality: A Contemporary Introduction. UK: Oxford University Press; 2014:97-106.

80. Courtois F, Charvier K, Leriche A, et al. Perceived physiological and orgasmic sensations at ejaculation in spinal cord injured men. J Sex Med 2008;5:2419-30.

81. Schover LR. Sexual healing in patients with prostate cancer on hormone therapy. Am Soc Clin Oncol Educ Book 2015;35:e562-6.

82. Reisman Y, Gianotten WL. Sexual tools and toys in oncosexology. In: Reisman Y, Gianotten WL, editors. Cancer, Intimacy and Sexuality. Switzerland: Springer; 2017:223-33.

83. Segal RL, Tajkarimi K, Burnett AL. Viberect penile vibratory stimulation system: evaluation of its erectogenic efficacy. Can J Urol 2013;20:6844-7.

84. Trost LW, Munarriz R, Wang R, et al. External mechanical devices and vascular surgery for erectile dysfunction. J Sex Med 2016;13:1579-617.

85. Ismail EA, El-Sakka AI. Innovative trends and perspectives for erectile dysfunction treatment: A systematic review. Arab J Urol 2016;14:84-93.

86. Nason GJ, McNamara F, Twyford M, et al. Efficacy of vacuum erectile devices (VEDs) after radical prostatectomy: the initial Irish experience of a dedicated VED clinic. Int J Impot Res 2016;28:205-8.

87. Qian SQ, Gao L, Wei Q, et al. Vacuum therapy in penile rehabilitation after radical prostatectomy: review of hemodynamic and antihypoxic evidence. Asian J Androl 2016;18:446-51.

88. Gandaglia G, Suardi N, Cucchiara V, et al. Penile rehabilitation after radical prostatectomy: does it work? Transl Androl Urol 2015;4:110-23.

89. Raina R, Pahlajani G, Agarwal A, et al. Long-term potency after early use of a vacuum erection device following radical prostatectomy. BJU Int 2010;106:1719-22.

90. Baniel J, Israilov S, Segenreich E, et al. Comparative evaluation of treatments for erectile dysfunction in patients with prostate cancer after radical retropubic prostatectomy. 
BJU Int 2001;88:58-62.

91. Lewis R. Twenty years of vacuum therapy for erectile dysfunction in the United States. In: Porst H, editor. Penile Disorders. Berlin Heidelberg: Springer 1997:163-74.

92. Hoyland K, Vasdev N, Adshead J. The use of vacuum erection devices in erectile dysfunction after radical prostatectomy. Rev Urol 2013;15:67-71.

93. Shaeer O. Congenital penile drop: defective suspensory ligament versus severe proximal curvature, a case series. J Sex Med 2012;9:618-24.

94. Nugteren HM, Pascal AL, Weijmar Schultz WC, et al. Surgery for an "acute erection angle," when counseling fails. J Sex Med 2010;7:1311-4.

95. Jannini EA, Buisson O, Rubio-Casillas A. Beyond the G-spot: clitourethrovaginal complex anatomy in female orgasm. Nat Rev Urol 2014;11:531-8.

96. Klapilova K, Brody S, Krejcova L, et al. Sexual satisfaction, sexual compatibility, and relationship adjustment in couples: the role of sexual behaviors, orgasm, and men's discernment of women's intercourse orgasm. J Sex Med 2015;12:667-75.

97. Gerressu M, Mercer CH, Graham CA, et al. Prevalence of masturbation and associated factors in a British national probability survey. Arch Sex Behav 2008;37:266-78.

98. Weiss P, Brody S. Female sexual arousal disorder with and without a distress criterion: prevalence and correlates in a representative Czech sample. J Sex Med 2009;6:3385-94.

99. Kelly DA. Intromittent organ morphology and biomechanics: defining the physical challenges of copulation. Integr Comp Biol 2016;56:705-14.

100. Rosen RC, Cappelleri JC, Smith MD, et al. Development and evaluation of an abridged, 5-item version of the International Index of Erectile Function (IIEF-5) as a diagnostic tool for erectile dysfunction. Int J Impot Res 1999;11:319-26.

101. Mulhall JP. Saving your sex life: a guide for men with prostate cancer. CIACT; 2011.

102. Mulhall JP, Jenkins LC. Vacuum erection device training. In: Mulhall JP, Jenkins LC, editors. Atlas of Office Based Andrology Procedures. Springer International Publishing; 2016:103-7.

103. Silver JK, Baima J. Cancer prehabilitation: an opportunity to decrease treatment-related morbidity, increase cancer treatment options, and improve physical and psychological health outcomes. Am J Phys Med Rehabil 2013;92:715-27.

104. Carli F, Scheede-Bergdahl C. Prehabilitation to enhance perioperative care. Anesthesiol Clin 2015;33:17-33.

105. Cohen L, Parker PA, Vence L, et al. Presurgical stress management improves postoperative immune function in men with prostate cancer undergoing radical prostatectomy. Psychosom Med 2011;73:218-25.

106. Angenete E, Angeras U, Borjesson M, et al. Physical activity before radical prostatectomy reduces sick leave after surgery - results from a prospective, non-randomized controlled clinical trial (LAPPRO). BMC Urol 2016;16:50.

107. Santa Mina D, Matthew AG, Hilton WJ, et al. Prehabilitation for men undergoing radical prostatectomy: a multi-centre, pilot randomized controlled trial. BMC Surg 2014;14:89.

108. Paich K, Dunn RL, Skolarus T, et al. Preparing patients and partners for the recovery from the side-effects of prostate cancer surgery: a group approach. Urology 2016;88:36-42.

109. Walker LM, King N, Kwasny Z, et al. Intimacy after prostate cancer: a brief couples' workshop is associated with improvements in relationship satisfaction. Psychooncology 2017;26:1336-46.

110. Parahoo K, McDonough S, McCaughan E, et al. Psychosocial interventions for men with prostate cancer. Cochrane Database Syst Rev 2013;12:CD008529.

111. Wootten AC, Abbott JM, Farrell A, et al. Psychosocial interventions to support partners of men with prostate cancer: a systematic and critical review of the literature. J Cancer Surviv 2014;8:472-84.

112.Hedden L, Wassersug RJ, Mahovlich S, et al. Evaluating an educational intervention to alleviate distress among men with newly-diagnosed prostate cancer and their partners. J Clin Oncol 2017;35:abstr 194.

113. Wittmann D, He C, Coelho M, et al. Patient preoperative expectations of urinary, bowel, hormonal and sexual functioning do not match actual outcomes 1 year after radical prostatectomy. J Urol 2011;186:494-9.

114. Rhoden EL, Teloken C, Sogari PR, et al. The use of the simplified International Index of Erectile Function (IIEF5 ) as a diagnostic tool to study the prevalence of erectile dysfunction. Int J Impot Res 2002;14:245-50.

115.Lee TK, Breau RH, Eapen L. Pilot study on quality of life and sexual function in men-who-have-sex-with-men treated for prostate cancer. J Sex Med 2013;10:2094-100.

116. Ussher JM, Perz J, Kellett A, et al. Health-related quality of life, psychological distress, and sexual changes following prostate cancer: a comparison of gay and bisexual men with heterosexual men. J Sex Med 2016;13:425-34.

117. Ussher JM, Perz J, Rose D, et al. Threat of sexual disqualification: the consequences of erectile dysfunction and other sexual changes for gay and bisexual men with 
prostate cancer. Arch Sex Behav 2017;46:2043-57.

118. Hart TL, Coon DW, Kowalkowski MA, et al. Changes in sexual roles and quality of life for gay men after prostate cancer: Challenges for sexual health providers. J Sex Med 2014;11:2308-17.

119. Simon Rosser BR, Merengwa E, Capistrant BD, et al. Prostate cancer in gay, bisexual, and other men who have sex with men: a review. LGBT Health 2016;3:32-41.

120.Dowsett GW, Lyons A, Duncan D, et al. Flexibility in men's sexual practices in response to iatrogenic erectile dysfunction after prostate cancer treatment. Sex Med 2014;2:115-20.

121. Reece M, Herbenick D, Dodge B, et al. Vibrator use among heterosexual men varies by partnership status: results from a nationally representative study in the United States. J Sex Marital Ther 2010;36:389-407.

Cite this article as: Wassersug R, Wibowo E. Nonpharmacological and non-surgical strategies to promote sexual recovery for men with erectile dysfunction. Transl Androl Urol 2017;6(Suppl 5):S776-S794. doi: 10.21037/tau.2017.04.09
122. Reece M, Rosenberger JG, Schick V, et al. Characteristics of vibrator use by gay and bisexually identified men in the United States. J Sex Med 2010;7:3467-76.

123. Walker LM, Wassersug RJ, Robinson JW. Psychosocial perspectives on sexual recovery after prostate cancer treatment. Nat Rev Urol 2015;12:167-76.

124. Gupta R, Kirschen J, Barrow RC, 2nd, et al. Predictors of success and risk factors for attrition in the use of intracavernous injection. J Urol 1997;157:1681-6.

125.Irwin MB, Kata EJ. High attrition rate with intracavernous injection of prostaglandin E1 for impotency. Urology 1994;43:84-7.

126. Prabhu V, Alukal JP, Laze J, et al. Long-term satisfaction and predictors of use of intracorporeal injections for postprostatectomy erectile dysfunction. J Urol 2013;189:238-42. 